\title{
Validação de conteúdo de um instrumento de avaliação do esquema corporal para crianças com cegueira
}

Patricia Santos de Oliveira* Mey de Abreu Van Munster**

\begin{abstract}
Resumo
O objetivo deste estudo foi descrever o processo de validação de conteúdo de um instrumento de avaliação do esquema corporal para crianças com cegueira congênita com idade entre 6 e 9 anos. A população foi constituída por sete professores universitários os quais receberam uma primeira versão do instrumento, eles analisaram cada item nos quesitos, clareza de linguagem, pertinência teórica, viabilidade de aplicação, e adequação ao constructo. A prova 1- obteve $80 \%$ de concordância; a Prova 2 recebeu $70 \%$, a prova $3-60 \%$ e a prova $4-75 \%$. Adotou-se como critério de permanência da prova o mínimo de $80 \%$ de concordância. A prova 1 permaneceu como na primeira versão, a prova 2 foi excluída e as provas 3 e 4 foram modificadas. Com base nas sugestões dos juízes e no índice de concordância elaborouse uma segunda versão do instrumento composta por três itens. Com isso, foi possível considerar que as adaptações sugeridas pelos juízes foram importantes para garantir a validade de conteúdo do instrumento.
\end{abstract}

Palavras- chave: Educação Especial, Educação Física adaptada, Cegueira, Avaliação, Esquema corporal.

\footnotetext{
* Mestre em Educação Especial pelo Programa de Pós-graduação em Educação Especial PPGEES/ UFSCar (2011). Membro desde 2007 do Núcleo de estudos em Atividade Física Adaptada - NEAFA. São Carlos, São Paulo.

** Professora Doutora do Departamento de Educação Física e Motricidade Humana/ Programa de Pós-Graduação em Educação Especial (UFSCar) São Carlos. Cordenadora do Núcleo de Estudos em Atividade Física Adaptada - NEAFA. São Carlos, São Paulo.
}

Revista Educação Especial | v. 25 | n. 44, | p. 563-586 | set./dez. 2012

Santa Maria

Disponível em: <http://www.ufsm.br/revistaeducacaoespecial> 


\section{Content validation of an instrument of evaluation of body scheme for blind children}

\section{Abstract}

The aim of this study was to describe the process of content validation of an instrument of evaluation of Body Scheme for children with congenital blindness with aged between 6 and 9 years old. The population was composed of seven judges who received a first version of the instrument, they analyzed each item in the categories, clarity of language, theoretical pertinence, viability of application, and adequacy of construction. Item 1 - "Exploring the body" obtained $80 \%$ agreement; item 2 - "Playing getting dressed" received $70 \%$ agreement; item 3 - "Imitating gestures" 60\% agreement; item 4 - "Puzzle" $75 \%$ agreement. It was adopted as a criterion of permanence in the proof at least $80 \%$ agreement. The item 1 remained as it was in the first version; item 2 was excluded and items 3 and 4 were modified. Based on the suggestions of the judges and the rate of agreement, a second version of the instrument composed of three items was elaborated. It was possible to consider the changes suggested by the judges were important to ensure the content validity of the instrument.

Keywords: Special Education; Adapted Physical Education; Blindness; Evaluation; Body scheme.

\section{Introdução}

A avaliação possui diferentes funções, na área de Educação Física adaptada o processo avaliativo é importante para a constatação de necessidades especiais e estabelecimento de uma base para a instrução (SHORT, 2004). Castro (2005) destaca que por meio da avaliação é possível esboçar um desempenho inicial e também acompanhar o progresso do aluno, além de poder ser utilizada para atribuir conceitos, níveis, estabelecer estágios evolutivos e propor recomendações.

Masini (1995) levanta algumas questões com relação à utilização de instrumentos de avaliação voltados a pessoas sem deficiência visual que são adaptados para a aplicação em pessoas cegas ou com baixa visão. Segundo a autora estas pesquisas não levam em conta as diferenças de percepção da pessoa com deficiência visual e do vidente, podendo interferir na validade do estudo. Assim, a mesma autora acrescenta que o desenvolvimento de instrumentos de avaliação para pessoas com deficiência visual são de extrema importância para a produção de conhecimento e para a viabilização de estudos futuros. 
Quando se trata da elaboração de um instrumento de avaliação deve-se levar em consideração, entre outros aspectos, a validade de conteúdo do mesmo, a qual pode ser garantida pela técnica empregada no processo de construção do teste. Segundo Pasquali (2003), a elaboração de um instrumento consiste nas seguintes etapas: Definição dos objetivos/ domínios; Definição do universo de conteúdo; Definição da representatividade de conteúdo; Elaboração da tabela de especificações; Construção do teste e Análise teórica dos itens.

A análise teórica dos itens é uma etapa importante no processo de validação de conteúdo de um instrumento e pode ser realizada, dentre outras formas, por meio da análise de juízes, a qual tem por objetivo avaliar a pertinência do item, a adequação ao construto, entre outros aspectos (ALEXANDRE; COLUCI, 2011). Pasquali (1998) recomenda que o quadro de juízes seja formado por pessoas especialistas na área do constructo, uma vez que estes deverão analisar se os itens propostos se referem ou não a o que se pretende avaliar.

Com relação a quantidade de juízes que irá compor o quadro para a análise do instrumento, é necessário que se estabeleça um número mínimo para garantir a representatividade da análise. Assim, de acordo com Alexandre e Coluci (2011) com a participação de cinco ou menos colaboradores, todos devem concordar para que a análise seja representativa. Já Pasquali (1998) sugere que o quadro seja formado por no mínimo 6 juízes.

Em um estudo desenvolvido por Oliveira e Munster (2010) foi apresentada uma proposta de elaboração do Instrumento de avaliação do esquema corporal para crianças com cegueira congênita na faixa etária de 6 a 9 anos. Neste estudo as autoras, com base em pesquisa bibliográfica, realizaram a definição operacional dos itens onde os mesmos foram definidos em termos de operações concretas, ou seja, de comportamentos físicos através dos quais o constructo (esquema corporal) poderia ser expresso (PASQUALI,1998). Após a operacionalização do constructo as provas foram organizadas em uma proposta inicial de avaliação.

No estudo apresentado anteriormente, foi descrito o processo inicial de elaboração, escolha e adaptação das provas e como os itens foram estruturados dando origem a uma primeira versão do instrumento, faltando assim, a etapa referente à análise teórica dos itens. Diante do exposto, o objetivo do presente trabalho é descrever o processo de validação de conteúdo de um instrumento de avaliação do esquema corporal para crianças com cegueira congênita com idade entre 6 e 9 anos. 


\section{Métodos}

\section{Caracterização da pesquisa}

Esta pesquisa caracteriza-se como uma pesquisa de abordagem exploratória descritiva. Este tipo de pesquisa tem como finalidade aumentar a familiaridade do pesquisador com um ambiente, ou fenômeno, a fim de desenvolver pesquisas futuras mais precisas ou modificar e clarificar conceitos (MARCONI; LAKATOS, 1990).

\section{Participantes}

Apopulação do estudo foi constituída por 7 professores Universitários, todos com titulação de Doutor, peritos na área de psicomotricidade/ esquema corporal e ou deficiência visual, atuantes nas áreas de Educação Física, Educação Especial, Educação e Terapia Ocupacional.

\section{Cuidados Éticos}

O projeto foi submetido ao Comitê de ética em Pesquisa com seres humanos da UFSCar sendo aprovado pelo parecer $n^{\circ} 361 / 2009$.

\section{Procedimentos}

Os procedimentos para a construção do instrumento de avaliação teve como base os princípios psicométricos. De acordo com Pasquali (1998), o processo de elaboração de testes de avaliação ocorre por meio de três processos os quais o autor denomina de procedimentos teóricos, procedimentos empíricos (experimentais) e procedimentos analíticos (estatístico). Para este estudo será considerada somente a análise teórica, compreendendo a validade de conteúdo do instrumento.

Em estudos anteriores foi realizada a elaboração dos itens e construção do instrumento, posteriormente a esta fase o instrumento foi submetido ao processo de validação de conteúdo por meio da análise de juízes sugerido por Pasquali (1998), processo pelo qual será descrito no presente estudo. 


\section{Análise por juízes}

Após o aceite na participação na pesquisa, foi enviado por e-mail aos juízes um protocolo contendo uma carta de apresentação o resumo do trabalho, algumas considerações sobre a construção do instrumento, a descrição de cada prova, e um formulário para análise dos itens.

Neste protocolo foi solicitado que os juízes avaliassem cada item em quatro quesitos diferentes:

- Clareza de linguagem: O quesito clareza de linguagem pretendeu ressaltar o entendimento do item por parte do profissional que irá utilizar o instrumento, dessa forma, foi necessário que o juiz avaliasse se o item foi exposto de forma clara e evidente pelas pesquisadoras, não suscitando dúvida ou dificuldade durante a leitura da avaliação.

- Pertinência teórica: Neste quesito foi solicitado que o juiz analisasse se o item estava adequado ao conteúdo que se encontra na literatura sobre o mesmo.

- Viabilidade de Aplicação: Com relação à viabilidade de aplicação, o juiz teve que analisar não somente a possibilidade, bem como a facilidade em se avaliar na criança cega o item proposto.

- Adequação ao constructo: Neste quesito foi solicitado que o juiz avaliasse a importância e pertinência de se analisar determinado aspecto do esquema corporal.

Em cada um desses quesitos havia três possibilidades de resposta, uma positiva, outra intermediária e uma negativa. É necessário ressaltar, que no protocolo de análise foi reservado um espaço a frente de cada quesito para que os juízes realizassem sugestões e comentários. Os quais foram tabulados e utilizados para a reestruturação do instrumento. Por ultimo foi solicitado que os juízes indicassem se o item podia ser classificado como de Reconhecimento, Construção ou Reprodução.

Para cada item foi calculado o Índice de Validade de Conteúdo (IVC), que indica, item a item, qual a porcentagem de respostas positivas entre os juízes. Este índice auxilia na identificação dos possíveis itens que estejam necessitando de alterações na fase de validação e adaptação do instrumento. Por meio dele é possível medir a porcentagem de juízes que estão em concordância sobre determinados aspectos do instrumento e de seus itens. O escore do IVC é calculado por meio da soma de concordância 
dos itens que foram marcados por respostas positivas pelos juízes, dividido pelo número total de respostas. Os itens que receberam respostas negativas devem ser revisados ou eliminados. Por este método, os itens e o instrumento como um todo, são considerados válidos, se obtiverem um IVC de no mínimo 0,80 (ALEXANDRE; COLUCI, 2011; RUBIO et al, 2003). a seguir:

A fórmula para avaliar cada item individualmente será apresentada

$$
\text { IVC }=\frac{\text { Número de respostas positivas }}{\text { Número total de respostas }}
$$

\section{Resultados e discussão}

Nos quadros e gráficos seguintes estão representadas, consecutivamente, as respostas dos juízes em relação à clareza de linguagem, pertinência teórica, viabilidade de aplicação e adequação ao constructo em cada uma das provas:

\begin{tabular}{|c|c|c|c|c|}
\hline JuÍzES & \multicolumn{4}{|c|}{ PROVA 1 - PASSEIO PELO CORPO } \\
\hline & $\begin{array}{c}\text { Clareza da } \\
\text { linguagem }\end{array}$ & $\begin{array}{c}\text { Pertinência } \\
\text { Teórica }\end{array}$ & $\begin{array}{c}\text { Viabilidade } \\
\text { de Aplicação }\end{array}$ & $\begin{array}{c}\text { Adequação } \\
\text { ao constructo }\end{array}$ \\
\hline Juiz 1 & Adequado & Pertinente & Viável & Adequado \\
\hline Juiz 2 & Adequado & Pertinente & Viável & $\begin{array}{c}\text { Pouco } \\
\text { Adequado }\end{array}$ \\
\hline Juiz 3 & $\begin{array}{c}\text { Pouco } \\
\text { Adequado }\end{array}$ & Pertinente & Viável & Adequado \\
\hline Juiz 4 & Adequado & Pertinente & Viável & Adequado \\
\hline Juiz 5 & Adequado & Pertinente & Viável & $\begin{array}{c}\text { Pouco } \\
\text { Adequado }\end{array}$ \\
\hline Juiz 6 & $\begin{array}{c}\text { Pouco } \\
\text { Adequado }\end{array}$ & Pertinente & Pouco viável & Adequado \\
\hline Juiz 7 & Adequado & Pertinente & Viável & Adequado \\
\hline $\begin{array}{c}\text { Concordância } \\
\text { entre Juizes }\end{array}$ & $\mathbf{7 1 \% ~ - - - - - ~ 5 ~}$ & $\mathbf{1 0 0 \% ~ - - - - - ~ 7 ~}$ & $\mathbf{8 6 \% ~ - - - - - ~ 6 ~}$ & $\mathbf{7 1 \% ~ - - - - ~ 5 ~}$ \\
\hline
\end{tabular}

QUADRO 1: Análise dos juízes em cada quesito, assim como a porcentagem de concordância entre respostas positivas obtidas na prova 1. 


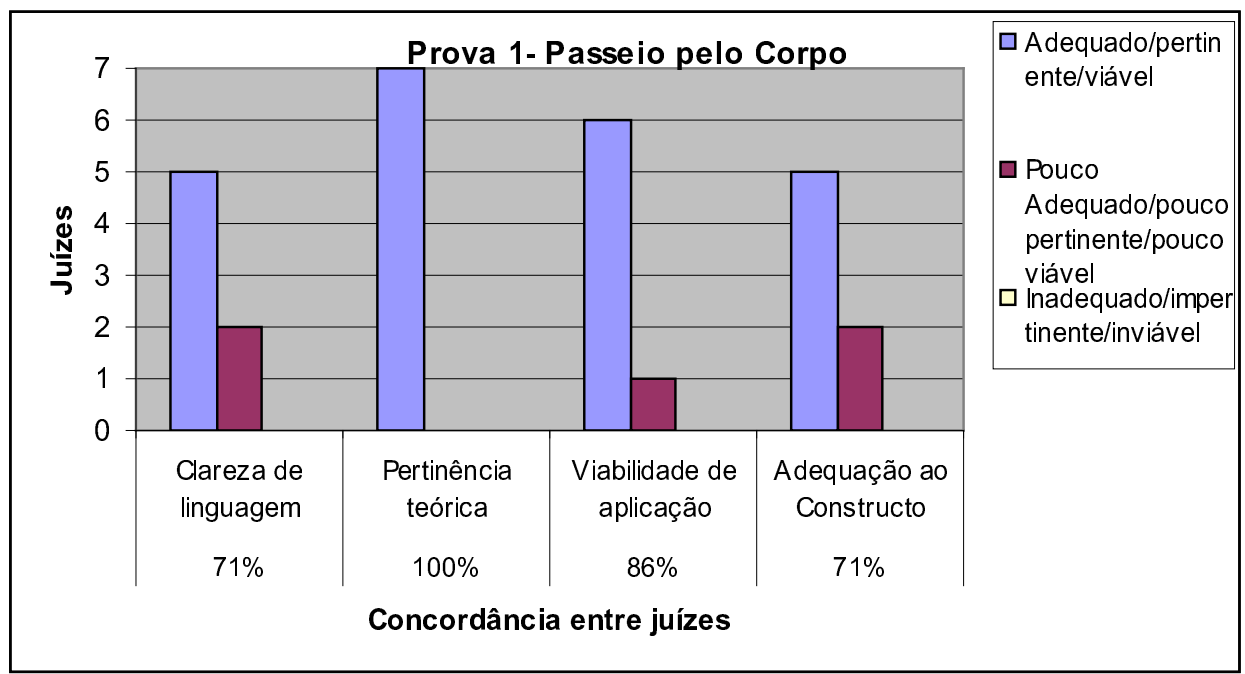

FIGURA 1: Gráfico com os valores referentes ao percentual de concordância entre os juízes obtidos em cada quesito da Prova 1.

\begin{tabular}{|c|c|c|c|c|}
\hline & \multicolumn{3}{|c|}{ PROVA 2 - BRINCANDO DE SE VESTIR } \\
\hline & $\begin{array}{c}\text { Clareza da } \\
\text { linguagem }\end{array}$ & $\begin{array}{c}\text { Pertinência } \\
\text { Teórica }\end{array}$ & $\begin{array}{c}\text { Viabilidade } \\
\text { de Aplicação }\end{array}$ & $\begin{array}{c}\text { Adequação } \\
\text { ao } \\
\text { constructo }\end{array}$ \\
\hline Juiz 1 & Adequado & Impertinente & Viável & Inadequado \\
\hline Juiz 2 & Adequado & Pertinente & Viável & $\begin{array}{c}\text { Pouco } \\
\text { Adequado }\end{array}$ \\
\hline Juiz 3 & $\begin{array}{c}\text { Pouco } \\
\text { Adequado }\end{array}$ & Pertinente & Viável & Adequado \\
\hline Juiz 4 & Adequado & Pertinente & Viável & Adequado \\
\hline Juiz 5 & Adequado & Pertinente & Viável & \\
\hline Juiz 6 & $\begin{array}{c}\text { Pouco } \\
\text { Adequado }\end{array}$ & Pertinente & Pouco viável & Adequado \\
\hline Juiz 7 & $\begin{array}{c}\text { Pouco } \\
\text { Adequado }\end{array}$ & Pertinente & Viável & Adequado \\
\hline $\begin{array}{c}\text { Concordância } \\
\text { entre Juízes }\end{array}$ & $\mathbf{5 7 \% ~ - - - - ~ 4}$ & $\mathbf{8 6 \%}----\mathbf{6}$ & $\mathbf{8 6 \%}----\cdot \mathbf{6}$ & $\mathbf{5 7 \% ~ - - - - ~ 4}$ \\
\hline
\end{tabular}

QUADRO 2: Análise dos juízes em cada quesito, assim como a porcentagem de concordância obtidas na prova 2. 


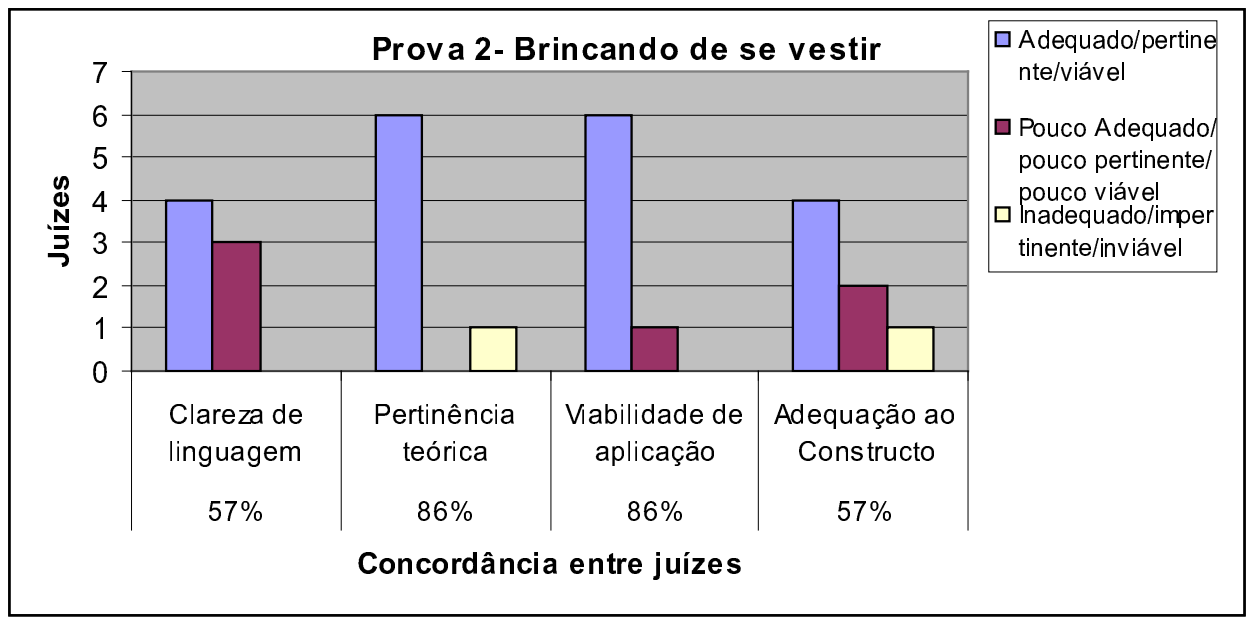

FIGURA 2 : Gráfico com os valores referentes ao percentual de concordância entre os juízes obtidos em cada quesito da Prova 2.

\begin{tabular}{|c|c|c|c|c|}
\hline \multirow[t]{2}{*}{ JUÍZES } & \multicolumn{4}{|c|}{ PROVA 3 - IMITAÇÃO DE GESTOS } \\
\hline & $\begin{array}{l}\text { Clareza da } \\
\text { linguagem }\end{array}$ & $\begin{array}{c}\text { Pertinência } \\
\text { Teórica }\end{array}$ & $\begin{array}{c}\text { Viabilidade } \\
\text { de Aplicação }\end{array}$ & $\begin{array}{l}\text { Adequação } \\
\text { ao constructo }\end{array}$ \\
\hline Juiz 1 & Adequado & Pertinente & Viável & Adequado \\
\hline Juiz 2 & Adequado & Pertinente & Viável & Adequado \\
\hline Juiz 3 & Inadequado & $\begin{array}{c}\text { Pouco } \\
\text { pertinente }\end{array}$ & Pouco viável & $\begin{array}{c}\text { Pouco } \\
\text { Adequado }\end{array}$ \\
\hline Juiz 4 & Adequado & $\begin{array}{c}\text { Pouco } \\
\text { pertinente }\end{array}$ & Viável & $\begin{array}{c}\text { Pouco } \\
\text { Adequado }\end{array}$ \\
\hline Juiz 5 & Adequado & Pertinente & Viável & $\begin{array}{c}\text { Pouco } \\
\text { Adequado }\end{array}$ \\
\hline Juiz 6 & $\begin{array}{c}\text { Pouco } \\
\text { Adequado }\end{array}$ & Pertinente & Pouco viável & Adequado \\
\hline Juiz 7 & $\begin{array}{c}\text { Pouco } \\
\text { Adequado }\end{array}$ & $\begin{array}{l}\text { Pouco } \\
\text { pertinente }\end{array}$ & Viável & Adequado \\
\hline $\begin{array}{l}\text { Concordância } \\
\text { entre Juízes }\end{array}$ & $57 \%$ & $57 \%$ & 71\% ---- 5 & $57 \%$---- 4 \\
\hline
\end{tabular}

QUADRO 3: Análise dos juízes em cada quesito, assim como a porcentagem de concordância obtidas na prova 3. 


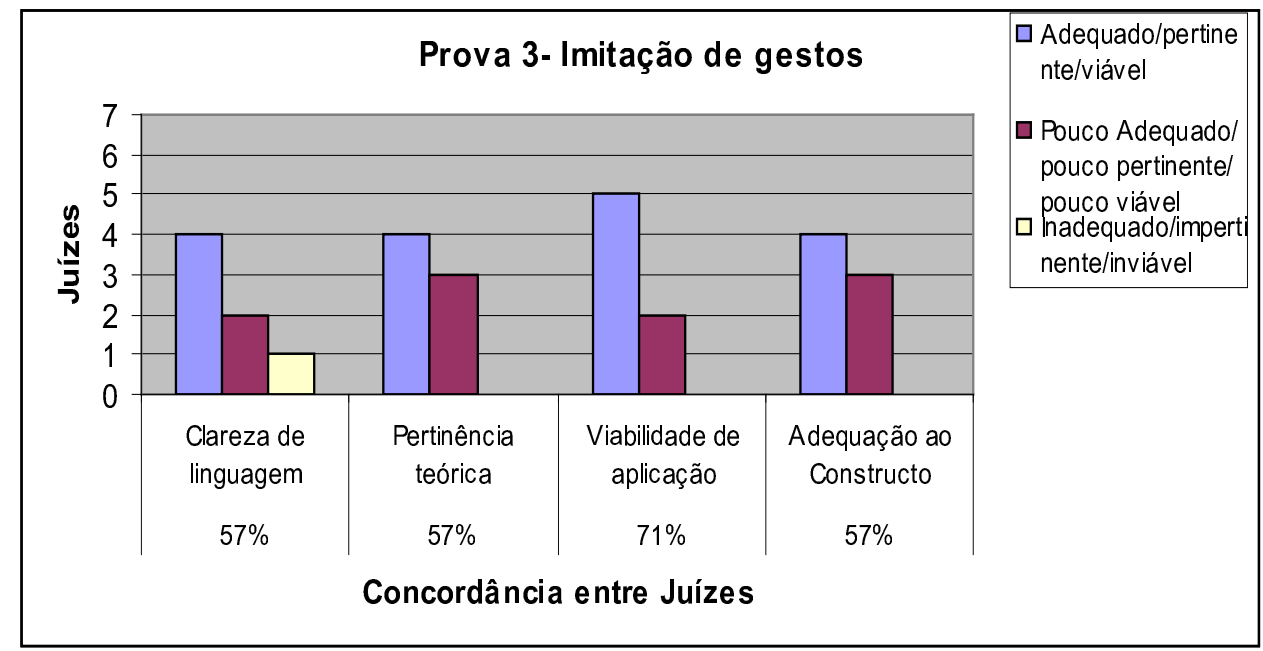

FIGURA 3: Gráfico com os valores referentes ao percentual de concordância entre os juízes obtidos em cada quesito da Prova 3.

\begin{tabular}{|c|c|c|c|c|}
\hline JUízES & \multicolumn{4}{|c|}{ PROVA 4 - QUEBRA CABEÇA } \\
\hline & $\begin{array}{c}\text { Clareza da } \\
\text { linguagem }\end{array}$ & $\begin{array}{c}\text { Pertinência } \\
\text { Teórica }\end{array}$ & $\begin{array}{c}\text { Viabilidade } \\
\text { de Aplicação }\end{array}$ & $\begin{array}{c}\text { Adequação } \\
\text { ao constructo }\end{array}$ \\
\hline Juiz 1 & Adequado & Pertinente & Viável & Adequado \\
\hline Juiz 2 & Adequado & Pertinente & Viável & $\begin{array}{c}\text { Pouco } \\
\text { Adequado }\end{array}$ \\
\hline Juiz 3 & Adequado & Pertinente & Viável & Adequado \\
\hline Juiz 4 & Adequado & Pertinente & Viável & Adequado \\
\hline Juiz 5 & Adequado & $\begin{array}{c}\text { Pouco } \\
\text { pertinente }\end{array}$ & Viável & $\begin{array}{c}\text { Pouco } \\
\text { Adequado }\end{array}$ \\
\hline Juiz 6 & $\begin{array}{c}\text { Pouco } \\
\text { adequado }\end{array}$ & Pertinente & Pouco viável & $\begin{array}{c}\text { Pouco } \\
\text { Adequado }\end{array}$ \\
\hline Juiz 7 & Adequado & Pertinente & Pouco viável & Adequado \\
\hline $\begin{array}{c}\text { Concordância } \\
\text { entre Juízes }\end{array}$ & $\mathbf{8 6 \% ~ - - - - - ~ 6 / 7 ~}$ & $\mathbf{8 6 \% ~ - - - - - ~ 6 / 7 ~}$ & $\mathbf{7 1 \% ~ - - - - - ~ 5 / 7 ~}$ & $\mathbf{5 7 \% ~ - - - - - ~ 4 / 7 ~}$ \\
\hline
\end{tabular}

QUADRO 4: Análise dos juízes em cada quesito, assim como a porcentagem de concordância obtidas na prova 4. 


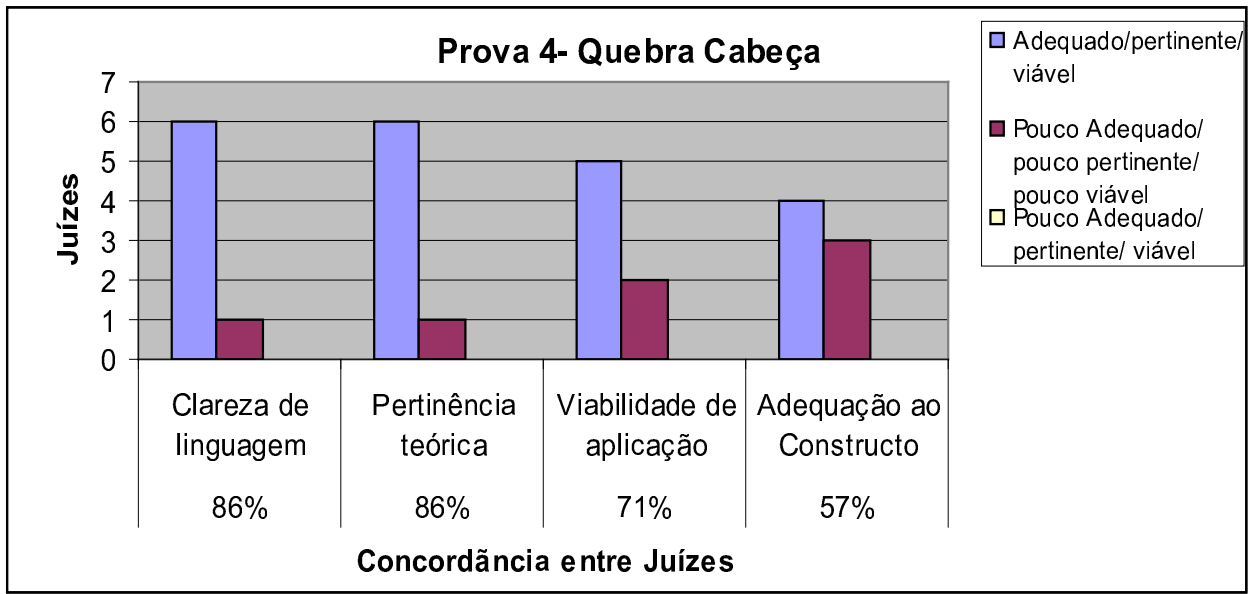

FIGURA 4: Gráfico com os valores referentes ao percentual de concordância entre os juízes obtidos em cada quesito da Prova 4.

Por meio da análise dos gráficos é possível observar, que há uma prevalência de respostas positivas e intermediárias, onde apenas a prova 2-Brincando de se vestir e 3-Imitação de gestos, obtiveram respostas negativas, cada uma delas por um juiz. A prova 2 obteve inadequado no quesito pertinência teórica e Adequação ao constructo e a prova 3 obteve inadequado ao quesito clareza de linguagem.

A prova 1 obteve $71 \%$ de concordância no quesito clareza de linguagem $100 \%$ em pertinência teórica, $86 \%$ em viabilidade de aplicação e $71 \%$ em adequação ao constructo. A prova 2 obteve $57 \%$ de concordância no quesito clareza de linguagem $86 \%$ em pertinência teórica, em $86 \%$ viabilidade de aplicação e $57 \%$ em adequação ao constructo. A prova 3 obteve $57 \%$ concordância no quesito clareza de linguagem $57 \%$ em pertinência teórica, $71 \%$ em viabilidade de aplicação e $57 \%$ em adequação ao constructo. A prova 4 obteve $86 \%$ concordância no quesito clareza de linguagem $86 \%$ em pertinência teórica, $71 \%$ em viabilidade de aplicação e $57 \%$ em adequação ao constructo.

Para calcular o Índice de validade de conteúdo (IVC) de cada prova foi somada a porcentagem de respostas consideradas adequadas obtidas em cada quesito, depois foi dividido pelo número de quesitos avaliados.

$$
\text { IVC Prova }=\frac{(\% \mathrm{CL}+\% \mathrm{PT}+\% \mathrm{VA}+\% \mathrm{AC})}{\mathrm{N}^{\circ} \text { de quesitos }(=4)}
$$




\begin{tabular}{|c|c|c|c|c|}
\hline & Prova 1 & Prova 2 & Prova 3 & Prova 4 \\
\hline $\begin{array}{c}\text { IVC - Índice } \\
\text { de validade } \\
\text { de conteúdo }\end{array}$ & $80 \%$ & $70 \%$ & $60 \%$ & $75 \%$ \\
\hline
\end{tabular}

TABELA 1: Média dos Índices de validade de conteúdo de cada prova

Alexandre e Colucci (2011) propõem que seja estipulada uma taxa de concordância aceitável entre os juízes. No caso de seis ou mais, recomenda-se uma taxa não inferior a 0,78. Pasquali $(1998,2003)$ sugere uma concordância mínima de 0,80 . No entanto, os valores recomendados devem ser de 0,90 ou mais. Assim para este estudo será considerado a concordância mínima de $80 \%$.

Após a análise pelo comitê de juízes, as provas que obtiveram IVC menores que 0,80 foram reestruturadas com base nas sugestões oferecidas pelo comitê, ou eliminadas do instrumento. Dessa forma, apenas a prova 2 foi excluída, e as provas 3 e 4 foram reestruturadas.

Como exposto anteriormente algumas das considerações e sugestões dadas pelos juízes foram consideradas para a reestruturação das provas, as mesmas serão apresentadas a seguir:

Na prova 1- Passeio pelo corpo, os juízes 3 e 4 sugeriram que a bola utilizada fosse de $5 \mathrm{~cm}$ de diâmetro, ao invés de $3 \mathrm{~cm}$, como exposto na primeira versão do instrumento; o juiz 6 sugeriu que fosse explicado que o banco onde seria realizado a prova fosse "sem encosto", visto que isso não ficou claro na $1^{\text {a }}$ versão; o mesmo também sugeriu que fosse especificado o lugar exato do toque da bola na perna e no braço, o juiz 3 sugeriu que fosse utilizada linguagem menos formal, que as provas fossem contextualizadas em brincadeiras, e que acrescentasse o "bumbum" às partes do corpo a serem tocadas. O juiz 5 sugeriu descrever a resposta esperada para cada tarefa proposta.

Na prova 2- Brincando de se vestir, o juiz 1 apresentou que a prova era pouco representativa uma vez que envolvia aspectos sociais e culturais, sendo pouco relevante para a avaliação do esquema corporal, o juiz 3 sugeriu que fosse utilizada linguagem menos formal, e que as provas fossem contextualizadas em brincadeiras. O juiz 6 apresentou que a prova em questão, relacionava-se diretamente a aspectos sócio culturais de cada criança, e dessa forma, algumas peças de roupa poderiam não fazer parte do cotidiano delas, e assim a criança poderia não acertar, não porque não saberia responder mas sim porque não conheceria o adereço apresentado.

Revista Educação Especial | v. 25 | n. 44, | p. 563-586 | set./dez. 2012

Santa Maria

Disponivel em: <http://www.ufsm.br/revistaeducacaoespecial> 
Na prova 3-Boneco articulado: Imitação de gestos o juiz 1 sugeriu a elaboração de posições "mais ricas" ; o juiz 3 sugeriu alterações na prova com foco no próprio corpo da criança, apresenta também que o item $B$ da prova 3 seria de difícil compreensão para crianças pequenas, e por ultimo acrescentou que a prova de imitação seria mais interessante para crianças videntes do que para crianças cegas. O juiz 6 acrescentou que o modelo fosse do próprio avaliador, e que a linguagem utilizada para descrição do item $A$ fosse modificada uma vez a criança não irá imitar o que o boneco está fazendo como descrito na primeira versão, mas sim, reproduzirá uma posição. O juiz 7 sugeriu que o termo "pose" fosse substituído por "posição", uma vez que o termo anterior poderia não ser compreendido pela criança, sugeriu também que a criança primeiro demonstrasse a pose nela para depois demonstrar no boneco.

No item 4- Quebra Cabeça, os juízes 6 e 7 sugeriram a substituição do quebra cabeça bidimensional por um boneco tridimensional desarticulado, os mesmos acrescentaram que materiais bidimensionais são difíceis de reconhecimento pela criança cega antes dos 8 anos.

As sugestões e respectivas alterações serão apresentadas a seguir primeiramente em forma descritiva e posteriormente em forma de quadro para melhor compreensão:

A prova 1 não sofreu alteração em sua estrutura, no entanto foram realizadas algumas adequações relacionadas ao material, e a outros pequenos ajustes para se adequar às sugestões dos juízes. Assim, foi especificado o uso de banco sem encosto, e do lugar exato do toque da bola no braço e na perna da criança, e foi realizada a alteração no material. 


\begin{tabular}{|c|c|c|}
\hline \multicolumn{3}{|c|}{ PROVA 1} \\
\hline Sugestões & $\begin{array}{l}\text { Alterações: Atendidal } \\
\text { Não atendida }\end{array}$ & Observações \\
\hline $\begin{array}{l}\text { Bola de } 5 \mathrm{~cm} \text { de } \\
\text { diâmetro }\end{array}$ & Atendida & \\
\hline Banco sem encosto & Atendida & $\begin{array}{l}\text { Facilitaria a realização } \\
\text { do teste }\end{array}$ \\
\hline $\begin{array}{l}\text { Especificação do lugar } \\
\text { exato do toque da bola } \\
\text { na perna e no braço }\end{array}$ & Atendida & $\begin{array}{l}\text { Contribui para } \\
\text { o processo de } \\
\text { padronização } \\
\end{array}$ \\
\hline $\begin{array}{l}\text { Uso de linguagem } \\
\text { menos formal, } \\
\text { acréscimo do bumbum }\end{array}$ & Atendida & \\
\hline $\begin{array}{l}\text { Contextualização das } \\
\text { provas em brincadeiras }\end{array}$ & Atendidas & $\begin{array}{l}\text { As provas foram } \\
\text { adaptadas de forma a } \\
\text { evidenciar o conteúdo } \\
\text { lúdico, no entanto é } \\
\text { necessário ressaltar } \\
\text { que a atitude lúdica no } \\
\text { momento de propor } \\
\text { as provas depende } \\
\text { também, dentre outros } \\
\text { fatores, da atitude do } \\
\text { avaliador }\end{array}$ \\
\hline $\begin{array}{l}\text { Descrição da resposta } \\
\text { esperada para cada } \\
\text { tarefa }\end{array}$ & Atendida & \\
\hline
\end{tabular}

QUADRO 5 : Apresentação das sugestões realizadas pelos juízes na prova 1, e se as mesmas foram atendidas ou não.

A prova 2 foi eliminada devido à menor aceitação pelos juízes quando comparada a prova 1 , que também é de reconhecimento, assim, optou-se por manter apenas uma prova com essa característica.

A prova 3 foi reestruturada com base nas sugestões, o modelo passou a ser o próprio avaliador, foram elaboradas posições mais ricas que envolviam tanto os membros superiores, quanto os membros inferiores e o tronco. $O$ item $B$ desta prova foi eliminado, pois a linguagem não estava clara, podendo suscitar dúvidas para o entendimento da criança. 


\begin{tabular}{|c|c|c|}
\hline \multicolumn{3}{|c|}{ PROVA 3} \\
\hline Sugestão & $\begin{array}{l}\text { Alteração: Atendidal } \\
\text { Não atendida }\end{array}$ & Observações \\
\hline $\begin{array}{l}\text { Elaboração de } \\
\text { posições "mais ricas". }\end{array}$ & Atendida & $\begin{array}{l}\text { Foi elaborado um total } \\
\text { de doze posições que } \\
\text { incluem movimentos de } \\
\text { membros superiores, } \\
\text { inferiores e tronco }\end{array}$ \\
\hline $\begin{array}{l}\text { Que o modelo fosse do } \\
\text { próprio avaliador. }\end{array}$ & Atendida & $\begin{array}{l}\text { Poderia facilitar a } \\
\text { compreensão da } \\
\text { posição pela criança } \\
\text { uma vez que o modelo } \\
\text { seria real }\end{array}$ \\
\hline $\begin{array}{l}\text { Substituir a frase: a } \\
\text { criança deverá imitar } \\
\text { o que o boneco está } \\
\text { fazendo descrita no } \\
\text { item A, por: A criança } \\
\text { deverá reproduzir uma } \\
\text { posição. }\end{array}$ & Atendida & \\
\hline $\begin{array}{l}\text { Alterações na prova } \\
\text { com foco no próprio } \\
\text { corpo da criança; } \\
\text { posições proposta pela } \\
\text { criança. }\end{array}$ & Não atendida & $\begin{array}{l}\text { A proposição } \\
\text { das posições a } \\
\text { partir da própria } \\
\text { criança aumentaria } \\
\text { consideravelmente } \\
\text { a subjetividade do } \\
\text { instrumento, uma vez } \\
\text { que há a necessidade } \\
\text { de possuir um } \\
\text { parâmetro comum de } \\
\text { avaliação. }\end{array}$ \\
\hline $\begin{array}{l}\text { Substituição do termo } \\
\text { "pose" por "posição". }\end{array}$ & Atendida & $\begin{array}{l}\text { O termo posição é } \\
\text { mais adequado }\end{array}$ \\
\hline $\begin{array}{l}\text { O item B seria de difícil } \\
\text { compreensão para } \\
\text { crianças pequenas. }\end{array}$ & Atendida & Item excluído \\
\hline
\end{tabular}

QUADRO 6: Apresentação das sugestões realizadas pelos juízes na prova 3, e se as mesmas foram atendidas ou não.

A prova 4 sofreu alterações com relação ao material, sendo incorporado o boneco tridimensional desarticulado. 


\begin{tabular}{|l|c|l|}
\hline \multicolumn{3}{|c|}{ PROVA 4 } \\
\hline \multicolumn{1}{|c|}{ Sugestão } & $\begin{array}{c}\text { Alteração: Atendidal } \\
\text { Não atendida }\end{array}$ & \multicolumn{1}{c|}{ Observação } \\
\hline $\begin{array}{l}\text { Substituição do } \\
\text { quebra cabeça } \\
\text { bidimensional por um } \\
\text { boneco tridimensional } \\
\text { desarticulado }\end{array}$ & Atendida & \\
\hline $\begin{array}{l}\text { Contextualização das } \\
\text { provas em brincadeiras }\end{array}$ & Atendida & $\begin{array}{l}\text { As provas foram } \\
\text { adaptadas de forma a } \\
\text { evidenciar o conteúdo } \\
\text { lúdico, no entanto é } \\
\text { necessário ressaltar } \\
\text { que a atitude lúdica no } \\
\text { momento de propor } \\
\text { as provas depende do } \\
\text { avaliador. }\end{array}$ \\
\hline
\end{tabular}

QUADRO 7: Apresentação das sugestões realizadas pelos juízes na prova 4, e se as mesmas foram atendidas ou não.

A seguir será apresentada a segunda versão do instrumento de Avaliação do Esquema Corporal para crianças com cegueira, as frases que foram acrescentadas na descrição das provas ou alteradas, após as considerações realizadas pelos juízes, estão sublinhadas:

\section{Avaliação do esquema corporal para crianças com cegueira}

Prova 1: Passeio pelo corpo

Esta primeira prova terá como objetivo avaliar o conhecimento das diferentes partes do corpo pela criança.

- A criança deverá estar sentada em um banco sem encosto e o avaliador sentado a frente dela. Para a realização dessa prova será necessário a utilização de uma bola de borracha, de superfície lisa, com diâmetro de 5 $\mathrm{cm}$. O material a ser utilizado deverá ser apresentado à criança antes do início do teste. Nesta prova é necessário que o avaliador instigue a criança a chegar à resposta desejada. Ex: Se o avaliador tocar na bochecha da criança e a mesma nomear esta parte como rosto, o avaliador poderá perguntar: Em qual parte de seu rosto? Em qual lado está?

Disponivel em: <http://www.ufsm.br/revistaeducacaoespecial> 
- O teste tem inicio no momento em que o avaliador pousa o objeto sobre a cabeça da criança (ver lista indicando sequência), o mesmo deverá esperar alguns segundos antes de perguntar o nome da parte do corpo em que a criança sente a bola. O passeio do objeto é realizado tocando a pele da criança e a pergunta só deverá ser realizada após o avaliador manter o objeto na parte do corpo que a criança deverá identificar. Se a criança não souber nomear a parte do corpo solicitada, o avaliador deverá seguir para outra parte do corpo perguntando: $\mathrm{E}$ agora, onde está a bolinha? Após completar todo o percurso o avaliador poderá dar mais uma chance a criança voltando nas partes do corpo que ela não conseguiu identificar na primeira vez.

Materiais: Banco sem encosto, uma bolinha de borracha, de superfície lisa e macia, com $5 \mathrm{~cm}$ de diâmetro.

\section{Indicação}

A) Agora nós vamos fazer uma brincadeira que se chama passeio pelo corpo esta bolinha (deixar que a criança toque e sinta a bolinha com as mãos) irá passear por todo seu corpo, e irá parar em alguns lugares, cada vez que ela parar eu irei te perguntar sobre qual parte do corpo a bolinha está parada, e você deverá me responder.

Vamos começar passeando pelo rosto:

Sequência: testa, olhos direito e esquerdo, nariz, boca, queixo, bochecha direita, orelha direita, bochecha esquerda, orelha esquerda.

B) Agora a bolinha vai passear por todo o corpinho, e como no passeio pelo rosto, cada vez que ela parar eu irei te perguntar em qual parte do corpo ela está parada, e você deverá me responder.

Seqüência: Cabeça, pescoço, ombro direito, braço direito, mão direita, perna (altura da coxa) (d), joelho (d) pé (d), barriga, peito, ombro esquerdo, braço esquerdo, mão esquerda, perna (Altura da coxa) (e) joelho (e), pé (e), costas, bumbum. 
Prova 2: Brincando de estátua

- É necessário que o avaliador esteja agachado de joelhos em frente à criança com o intuito de permanecer na mesma altura dela, a fim de facilitar a cópia do movimento.

- O avaliador deverá estar de frente com a criança.

Posições simétricas

$1^{a}$ posição: Braço esquerdo e direito elevado a frente do corpo até a altura do ombro.

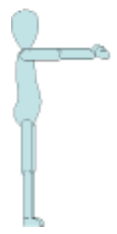

$2^{a}$ posição: Braço direito e esquerdo elevado a frente do corpo acima da cabeça.

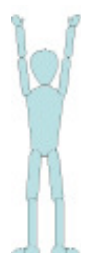

$3^{a}$ posição: Braço direito e esquerdo elevado lateralmente na altura do ombro com as palmas das mãos direcionadas para baixo.

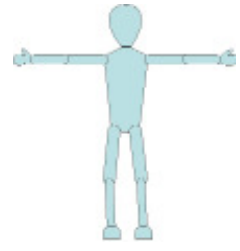

$4^{a}$ posição: Mão direita e esquerda tocando a nuca.

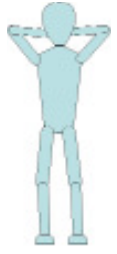

Revista Educação Especial | v. 25 | n. 44, | p. 563-586 | set./dez. 2012

Disponível em: <http://www.ufsm.br/revistaeducacaoespecial> 
$5^{a}$ posição: Pernas e pés afastados lateralmente (na largura do ombro) e braços estendidos ao longo do corpo.

$6^{a}$ posição: Pés paralelos, joelhos estendidos, flexão do quadril com projeção do tronco a frente, braços direcionados para o chão.

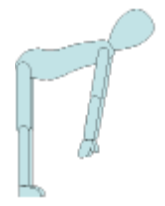

Indicação:

A) Agora, nesta brincadeira eu vou ficar em uma posição como se eu fosse uma estátua, e você tentará imitar igual a posição que eu estou. Podemos começar?(reprodução em espelho)

Posições assimétricas

$1^{a}$ posição: Braço esquerdo levantado a frente do corpo para cima e braço direito elevado lateralmente até a altura do ombro.

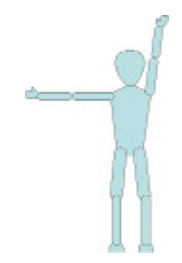

$2^{\mathrm{a}}$ posição: Braço esquerdo elevado a frente do corpo na altura do ombro, e braço direito elevado a frente do corpo para cima. 
$3^{a}$ posição: Perna direita afastada a frente do corpo perna esquerda afastada atrás do corpo.

$4^{a}$ posição: Pés paralelos, joelhos estendidos, flexão do quadril com projeção do tronco a frente, mão direita apoiada no joelho e mão esquerda estendida a frente.

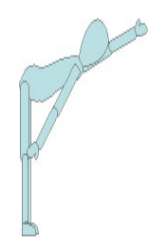

$5^{a}$ posição: Braço direito na cintura, e braço esquerdo estendido a frente do corpo.

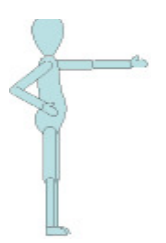

6a posição: Joelho direito flexionado encostado no chão, pé esquerdo apoiado no chão, mão direita e esquerda tocando o joelho esquerdo.

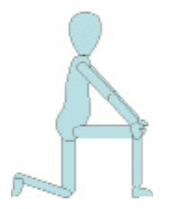

Fonte: OLIVEIRA, P. S.; MUNSTER, M. A. 2010, p. 3156-3175.

\section{Prova 3: Quebra Cabeça}

Reprodução de um modelo da figura humana por meio da montagem de um quebra cabeça tridimensional. Nesta prova a criança deverá situar cada uma das partes do corpo em seus lugares correspondentes. A criança deverá estar sentada de frente para uma mesa onde estarão dispostas as peças do quebra-cabeça.

Em um primeiro momento o avaliador apresenta o quebra cabeça montado à criança, levando a mão dela sobre cada parte do material e nomeando as partes tocadas: Aqui está o cabelo, estes são os olhos, o nariz e etc.

Disponível em: <http://www.ufsm.br/revistaeducacaoespecial> 
Material: Um quebra cabeça da figura humana, construído por meio da adaptação de um boneco de plástico.

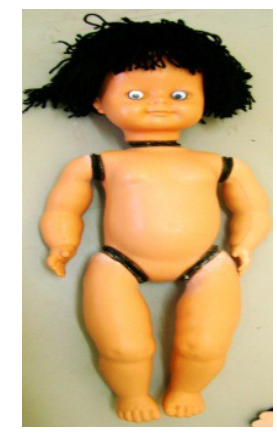

Fonte: OLIVEIRA, P. S.; MUNSTER, M. A. 2010, p. 3156-3175.

Indicação:

A) Agora nós vamos brincar de montar um quebra cabeça de um boneco (o avaliador permite que a criança toque o quebra-cabeça de forma a explorar e conhecer o brinquedo), agora eu vou desmontar e vou deixar as peças a sua frente toda embaralhadas, para que você possa montá-lo novamente.

\section{Cotação dos resultados:}

Para a cotação dos resultados do teste foram consideradas as respostas certas, as parcialmente corretas e as não certas. Dessa forma, serão assinalados com 2 as tentativas bem sucedidas, com 1 as parcialmente sucedidas e as não sucedidas com 0 . É necessário ressaltar que os acertos devem ser valorizados ainda que parciais, dessa forma as provas não devem ser consideradas de forma isolada, e sim em todo seu conjunto.

\section{Respostas corretas são:}

- As respostas imediatas, bem como as respostas hesitantes desde que a criança realize a prova como enunciada.

Respostas parcialmente corretas são:

- Inversão direita e esquerda

- Inversão posterior e anterior 
Respostas não corretas são:

- Não realização da tarefa solicitada

- Inversão na colocação de peças

- Inversão na nomeação das partes do corpo

Considerações a respeito de cada prova:

\section{Na prova 1}

- Serão consideradas como corretas as respostas equivalentes

Ex: bochecha- rosto

Peito- coração

\section{Na prova 2}

- Não deverá ser levado em consideração se a criança reproduziu em espelho ou heterolatral;

- Deverá ser considerada a direção de cada parte do corpo membros superiores, não se prendendo a detalhes referentes à posição de mãos e pés;

- Se a criança acertar a posição de um braço e errar do outro a resposta é considerada parcialmente correta.

\section{Na prova 3}

- Inversão de membros (direita e esquerda são consideradas respostas parcialmente corretas).

Considerações Finais

As adaptações sugeridas pelos juízes foram de extrema importância para garantir a validade de conteúdo do instrumento. As sugestões foram incorporadas à primeira versão, resultando em uma segunda versão do instrumento mais próximo do referencial perceptivo da criança com cegueira. Em estudos posteriores, pretende-se descrever a aplicação do Instrumento de avaliação do Esquema Corporal para crianças com cegueira a fim de verificar se este,é adequado ao referencial perceptivo da população em questão.

Disponível em: <http://www.ufsm.br/revistaeducacaoespecial> 
Durante a análise dos protocolos preenchidos pelos juízes, verificouse que o fato da pesquisadora não ter explicado de forma clara o que se esperava que o juiz considerasse/respondesse em cada quesito, gerou certa confusão. Assim, em próximos trabalhos recomenda-se que cada quesito seja explicado de forma clara, especificando o que se espera ser analisado em cada um dos critérios.

O método empregado para o desenvolvimento do estudo poderá abrir caminhos a outras pesquisas, com foco na construção e validação de conteúdo de instrumentos de avaliação na área de Educação Física Adaptada.

Com isso, é possível considerar que o estudo atingiu seu objetivo inicial e apresentou resultados que permitiu estabelecer com base na literatura uma descrição do processo de validação de conteúdo de uma proposta de avaliação do esquema corporal em que se prioriza a maneira de perceber e agir da criança com cegueira na faixa etária de 6 a 9 anos.

\section{Referências}

CASTRO, E. M. Atividade física adaptada. Ribeirão Preto: Tecmedd, 2005.

ALEXANDRE, N. M. C; COLUCI, M. Z. O. Validade de conteúdo nos processos de construção e adaptação de instrumentos de medidas. Revista Ciência \& Saúde Coletiva da Associação Brasileira de Pós-Graduação em Saúde Coletiva. 16(7): 3061-3068, 2011. Disponível em: http://www.scielo.br/pdf/ csc/v16n7/06.pdf. Acesso em: 29 maio 2012.

MASINI, E. F. S. Algumas questões sobre a avaliação do portador de deficiência visual. R. Bras. Est. Pedag. Brasília, v. 76, n. 184, p. 615-634, set./dez. 1995.

OLIVEIRA, P. S.; MUNSTER, M. A. Proposta de elaboração de um conjunto de provas para avaliação do esquema corporal em crianças com cegueira. In: IV Congresso Brasileiro de Educação Especial, São Carlos: 2010. p. 3156-3175.

PASQUALI, L.; Princípios de elaboração de escalas psicológicas. Rev. Psiq. Clinica. 25 (5) Edição Especial, p.206-213, 1998. Disponível em: http://www. hcnet.usp.br/ipq/revista/vol25/n5/conc255a.htm. Acesso em: 25 maio 2012.

PASQUALI, L.; Psicometria: teoria dos testes na psicologia e na educação. Petrópolis: Vozes. 2003. 
RUBIO, D. M. et al. Objectifying Content Validity: Conducting a Content Validity Study in Social Work Research. Social Work Research, v. 27 (2), 2003. p. 94-111.

SHORT, F. X. Medidas e Avaliação. In: In: WINNICK, J. Educação Física e esportes adaptados. Barueri: Manole, 2004.

\section{Correspondência}

Patricia Santos de Oliveira - Rua: Arábia $n^{\circ} 52$, Parque Paraiso, CEP: 06852-250. Itapecerica da Serra, São Paulo.

E-mail: patricia_educa@yahoo.com.br

Recebido em 03 de maio de 2012

Aprovado em 19 julho de 2012 